Fecha de recepción: diciembre 2018 Fecha de aceptación: marzo 2019 Versión final: abril 2019

\section{Evaluación de la creatividad en Diseño Industrial}

María Elena Onofre *

Resumen: Este trabajo explora los criterios de evaluación de la creatividad utilizados en la carrera de Diseño Industrial. El artículo comienza con una introducción disciplinar al Diseño Industrial que permite inferir la relevancia de la creatividad en el proceso de diseño. Luego despliega distintos enfoques sobre la conceptualización de la creatividad de los que surgen sus rasgos distintivos susceptibles de evaluar. Para el desarrollo de esta etapa se abordaron los enfoques psico-cognitivo (relacionado con las habilidades y capacidades cognitivas de los estudiantes de Diseño Industrial) y socio-cognitivo-interactivo (contextual, social y cultural). El artículo describe distintas perspectivas y teorías sobre la enseñanza de la creatividad, el análisis del proceso de evaluación de la creatividad y luego profundiza sobre las definiciones y posturas de expertos disciplinares respecto del objeto de la investigación: la evaluación de la creatividad en Diseño Industrial.

Palabras clave: Evaluación - creatividad - diseño industrial - criterios pedagógicos - habilidad - aprendizaje

[Resúmenes en inglés y portugués en las páginas 207 - 208]

${ }^{(*)}$ Licenciada Gestión de la Educación (CAECE). Posgrado en Gestión de las Instituciones Educativas (FLACSO). Graduada en Escuela Nacional de Bellas Artes Prilidiano Puyerredón (IUNA), Artes Visulaes. Coordinadora del área de Economía y Diseño, Facultad de Diseño y Comunicación, Universidad de Palermo. Coordinadora de la "Incubadora de Emprendimientos Creativos" y del Programa "Colegios" en Facultad de Diseño y Comunicación, Universidad de Palermo. Experta en marketing y comercialización de productos de consumo masivo.

\title{
Introducción
}

El objetivo de este trabajo es explorar cuáles son los criterios de evaluación de la creatividad utilizados en la carrera de Diseño Industrial. La investigación se realizó en la carrera de Diseño Industrial de la Facultad de Diseño y Comunicación de la Universidad de Palermo, en Buenos Aires. 
El proceso de diseño comienza con una necesidad, atraviesa ciertos grados de certidumbre y finaliza con la verificación del uso del objeto que le da respuesta (Mazzeo, 2007, p.67). La creatividad se configura como un factor determinante en la etapa de "generación y formulación" del proceso de diseño. Es precisamente en esta etapa de generación y formulación donde prevalece la idea de encontrar una respuesta que satisfaga las necesidades planteadas y aporte una solución novedosa al problema. Para los estudiosos de la creatividad, el rasgo distintivo que la caracteriza y que la mayoría convalida, es considerarla como una forma de pensamiento que se desencadena en un sujeto como consecuencia de la percepción de un problema y la posterior aportación de una solución novedosa (Santaella, 2006). Aquí radica la ineludible relación entre la creatividad y las disciplinas proyectuales. La variable creatividad forma parte de las rúbricas o matrices de evaluación de las asignaturas proyectuales de Diseño, sin embargo, en estas rúbricas difícilmente se indique de manera explícita cuáles son los indicadores, factores o rasgos de la creatividad relevantes para el campo disciplinar, y menos aún, cómo se miden. Así, durante el proceso de evaluación final, la creatividad suele valorarse en función de percepciones y concepciones subjetivas de los docentes, pocas veces argumentadas objetivamente.

La primera parte de este trabajo presenta definiciones de Diseño Industrial, y un detalle las características esenciales de las disciplinas proyectuales entre las que se distingue el Diseño Industrial como disciplina y su relación con la creatividad. Luego se presentan distintas definiciones de Creatividad en función de la evolución de la disciplina como campo científico. De estas definiciones surgen los rasgos relevantes susceptibles de evaluar. La conceptualización de la creatividad para el desarrollo de esta investigación, ha sido considerada desde dos enfoques: el psico-cognitivo, (Guilford, 1954) y el socio-cognitivo interactivo (contextual-social), Csikszentmihaly (1998). El primer enfoque se relaciona con las habilidades y capacidades cognitivas de los estudiantes de Diseño Industrial y el segundo enfoque se vincula con los aspectos institucionales, sociales y culturales que influyen en el pensamiento de diseño, al mismo tiempo que se ven modificados por la influencia de la creatividad al momento de presentar soluciones novedosas a problemas preexistentes. El trabajo recorre enfoques sobre la enseñanza de la creatividad desde la teoría constructivista y enfatiza la perspectiva del pensamiento lateral y el pensamiento paralelo desarrollados por Edward De Bono (1991). El trabajo avanza con la descripción de distintos enfoques de la evaluación de la creatividad anclados en los rasgos peculiares que distintos expertos en el tema detallan como aspectos distintivos de la creatividad. Luego se contempla la perspectiva de los "expertos disciplinares", legitimadores de esos rasgos que podrían resultar en indicadores para evaluar la creatividad. A esta fase corresponde el trabajo de campo instrumentado en entrevistas en profundidad a docentes y directores de carrera del campo disciplinar. Esta fase se desarrollará con posterioridad a la presentación de este trabajo.

\section{El Diseño Industrial}

La disciplina tiene su origen en la Revolución Industrial del S. XVIII (1760-1830), como resultado de la invención y utilización de maquinarias para la mecanización y producción "industrial" -en serie- de objetos y bienes de consumo. La característica distintiva de este 
nuevo sistema de producción es la separación de las tareas de ideación o preconcepción del objeto, de las de construcción o fabricación. Gay (2007), señala que con la separación de estas dos actividades, comienza una nueva etapa de división técnica del trabajo. La preconcepción o ideación de un producto, es lo que se denomina Diseño y refiere tanto a objetos y productos como a bienes y servicios. En tanto, la producción en serie configura el proceso de industrialización. Para el autor, el Diseño Industrial como disciplina, plantea un trabajo de preconcepción sistematizada que posibilita producir en serie con precisión. En el proceso de ideación de los objetos, además de resolver problemas funcionales (qué función cumple) y de funcionamiento (cómo funciona), es necesario contemplar aspectos formales (morfológicos), tecnológicos, estéticos, psicológicos, anatómicos y ergonómicos. El término Diseño Industrial comenzó a utilizarse para designar a la disciplina a partir de 1930 y se generalizó después de la Segunda Guerra Mundial. No es sino hasta comienzos del S. XX, con el surgimiento de La Bauhaus (1920), que la disciplina consolidó su perfil identitario como profesión.

Al definir al Diseño Industrial desde su función, Rojas Morales (2004) señala que la función del Diseño Industrial es la de satisfacer las necesidades de la sociedad a través del desarrollo y la producción de productos y servicios que mejoren la vida de las personas y de la sociedad en general. Desde esta perspectiva Gay (2007) afirma que la finalidad del Diseño Industrial es la producción de objetos que respondan a demandas (necesidades, deseos o aspiraciones) de la sociedad, atendiendo a los aspectos formales, funcionales, estéticos, tecnológicos, económicos, ergonómicos, simbólicos y legales. (p.13)

Para el desarrollo de este trabajo utilizaremos la definición del ICSID International Council of Industrial Design.

ICSID International Council of Industrial Design en su definición más extensa y completa del Diseño Industrial, señala que el diseño es una actividad creativa cuyo propósito es determinar las multifacéticas cualidades de los objetos, procesos, servicios y sus sistemas en ciclos de vida completos. El diseño es el factor central de la humanización innovadora de las tecnologías y un factor crucial del intercambio cultural y económico. El diseño industrial busca descubrir y evaluar las relaciones estructurales, organizacionales, funcionales, expresivas y económicas con el fin de: mejorar la sostenibilidad global y la protección ambiental (ética ambiental); otorgar beneficios y libertad a la comunidad humana, los usuarios finales tanto individuales como colectivos, los productores y los protagonistas del mercado (ética social); apoyar la diversidad cultural no obstante la globalización mundial (ética cultural); Otorgar a los productos, servicios y sistemas aquellas formas que sean expresión de (semiología) y coherentes con (estética) su propia complejidad. (icsid.org) Tal como señala esta definición, el Diseño Industrial es considerado una actividad eminentemente creativa cuya preocupación esencial son las personas a las que van dirigidos los productos y servicios diseñados.

En este sentido Rojas Morales (2004,) en su trabajo La creatividad desde la perspectiva de la enseñanza del diseño industrial propone la siguiente definición de creatividad para Diseño Industrial: "La creatividad es la capacidad del diseñador industrial de buscar, experimentar, analizar, reorganizar y relacionar información, imaginando escenarios distintos y generando soluciones innovadoras y pertinentes a diversos problemas, en determinados contextos, que contribuyan a transformar y mejorar el mundo". (p.172). La autora, a par- 
tir de esta investigación realizada en la Universidad Iberoamericana de México, presenta además la relación entre creatividad e innovación señalando que la creatividad es generar varias ideas, propuestas novedosas, respuestas originales, e innovar es convertir dichas ideas en productos y servicios novedosos.

Una característica de las más distintivas del Diseño es el desarrollo de métodos y sistemas normalizadores del proceso de Diseño. Desde La Bauhaus, el Diseño Industrial como disciplina ha buscado la forma de normalizar el proceso de diseño y distintas escuelas y corrientes científicas han analizado y desarrollado modelos para la "metodología del diseño". Rojas Morales (2004) presenta distintas corrientes que han desarrollado enfoques racionalistas cientificistas de la metodología del diseño. Asimow (1962), dividió el proceso en dos fases: planeación (que incluye el proceso creativo) y diseño detallado explicativo. Archer (1963) propone tres etapas: analítica, creativa y de ejecución. Alger y Hays (1964) proponen un proceso integrado por siete fases: definición del problema, especificación, proposición de alternativas, decisión, revisión, realización de prototipos y pre-serie. Burdek (1976) propuso un proceso integrado por seis fases: información, necesidades del usuario, aspectos funcionales, exploración de nuevas posibilidades, decisión, presentación de costo-beneficio, cálculo y prototipo.

Para el desarrollo de este trabajo tomaremos como marco de referencia las etapas del proceso de diseño planteadas por Mazzeo y Romano (2007) en su trabajo La enseñanza de las disciplinas proyectuales. Las autoras señalan que el proceso proyectual puede ser diseñado en etapas que a nivel didáctico ofrecen ordenamiento, proponen direcciones operativas y generan un espacio propicio para el intercambio de ideas. Desde su perspectiva las etapas del proceso son: información, formulación, desarrollo, materialización y verificación del proyecto. Todas estas etapas están atravesadas por el factor comunicación.

En la misma línea, Garaigordobil (1995) identifica 6 fases del proceso de diseño: a) cuestionamiento: en esta fase se identifica el problema y se formulan preguntas que contribuyan a resolverlo; b) recopilación de datos; c) incubación: fase en la que se van generando las ideas; d) iluminación: en esta fase surgen las soluciones al problema planteado; e) elaboración, en la que se realiza el producto y f) comunicación que es la presentación del resultado.

Antes de avanzar con el desarrollo del trabajo, resulta pertinente plantear el más actualizado de los modelos de proceso de diseño, denominado Design Thinking. Tim Brown (2008), considera al Pensamiento de Diseño como la metodología más eficaz para la resolución de problemas y el desarrollo de la innovación en cualquier disciplina. Considera al Pensamiento de Diseño como la herramienta capaz de transformar la forma de desarrollar productos, procesos, objetos, servicios y lo más relevante: estrategias. En este modelo, se habla de espacios de pensamiento, no de hitos lineales de un proceso convencional. Así las etapas son: inspiración, ideación e implementación, desde una perspectiva sistémica. Este enfoque convierte al proceso de diseño en una estrategia de naturaleza transdisciplinar. 


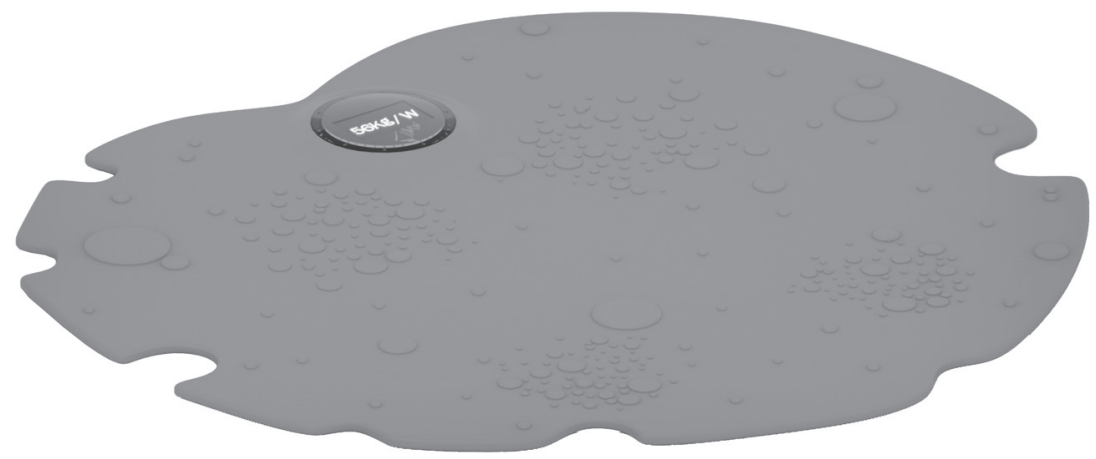

Imagen 1. Universidad de Palermo. Facultad de Diseño y Comunicación. Imágenes que crean productos 3. Volumen 32, (p.74). Marzo 2016. Laura Catalina Arenas Uribe. Buenos Aires. Argentina.

\section{La creatividad}

Este capítulo aborda distintos enfoques de la conceptualización de la creatividad, y profundiza sobre las perspectivas psico-cognitiva y socio-cognitiva-interactiva. Además, y ya centrándonos en el campo disciplinar del Diseño Industrial, se presentan enfoques que analizan la función de la creatividad en el proceso de diseño y en el producto final.

La creatividad es un fenómeno de significación compleja, plural y multidimensional (Garaigordobil, 1996). El término ha sido relacionado con múltiples significados ya que se aplica a realidades y campos muy diversos como el arte, la ciencia, la expresión personal y social, entre otros. La complejidad del término hace imposible una definición única, por lo que este trabajo abordará el tema desde dos enfoques, el psico-cognitivo (centrado en las habilidades intelectuales de la persona creativa) y el socio-cognitivo interactivo, que suma a estas habilidades, la influencia del contexto o entorno sociocultural en el proceso y el producto creativo.

El discurso de J.P. Guilford, como presidente de la Asociación Americana de Psicología (APA), en 1950, marca el punto de inflexión en desarrollo de la creatividad como campo científico de investigación. Desde un enfoque personalista psico-cognitivo, Guilford (1954), Torrance (1997), y Amabile (1981), y Drevdahl (1958), entre otros, definen a la creatividad en función de las aptitudes y habilidades características de las personas creadoras: fluidez, flexibilidad y originalidad. Más adelante, Rohdes (1961), Sternberg, R. y Lubart, T. (1977), Csikszentmihaly (1998), entre otros, abordan el tema desde un enfoque socio-cognitivo-interactivo en el que se tiene en cuenta a las personas, sus capacidades para desarrollar el pensamiento creativo, el contexto en el que se desenvuelven y su interacción con el entorno. Esta interacción contempla la valoración de los expertos en el campo disciplinar de referencia. Los expertos se configuran como los agentes legitimadores de la valoración de la creatividad. 
Para Guilford (1954), la creatividad, en sentido limitado, se refiere a las aptitudes que son características de los individuos creadores, como la fluidez, la flexibilidad, la originalidad y el pensamiento divergente".

Torrance (1997), define a la creatividad como un proceso que vuelve a alguien sensible a los problemas, deficiencias, grietas o lagunas en los conocimientos y lo lleva a identificar dificultades, buscar soluciones, hacer especulaciones o formular hipótesis, aprobar y comprobar estas hipótesis, a modificarlas si es necesario además de comunicar los resultados. Amabile (1983), establece tres destrezas cognitivas como componentes de creatividad: relevantes a un dominio, relevantes a la producción de ideas, relevantes a la motivación hacia la tarea.

Para Drevdahl (1964), citado en Garaigordobil (1996), la creatividad es la capacidad humana de producir contenidos mentales de cualquier tipo, que esencialmente puedan considerarse como nuevos y desconocidos para quienes los producen.

Desde el punto de vista del enfoque socio-cognitivo tomaremos como referencia a la definición de creatividad de Csikszentmihaly (1998) que señala que la creatividad es cualquier acto, idea o producto que cambia un campo ya existente, o que transforma un campo ya existente en uno nuevo.

Desde un enfoque psico-cognitivo, se diría que el eje de análisis son las personas y su capacidad para desarrollar el pensamiento y las habilidades creativas. A partir de 1950 se desarrolla la etapa más enérgica de investigaciones acerca de la creatividad. Desde la perspectiva psico-cognitiva, Guilford (1959) define a la creatividad como una forma de pensamiento que se desencadena en una persona como consecuencia de la percepción de un problema y se configura a partir de los componentes: fluidez, flexibilidad, elaboración y originalidad. Torrance (1962) define a la creatividad como un proceso en el que se descubren problemas, se formulan hipótesis, se intenta probarlas y se comunican los resultados. Desde el punto de vista de la teoría factorial, Torrance $(1962,1977)$ redefine los factores señalados por Guilford a) fluidez, b) flexibilidad, c) elaboración y d) originalidad. Además señala que las aptitudes del pensamiento creativo están claramente influenciadas por las condiciones ambientales y el contexto social y educativo. Sostiene que la creatividad es un proceso de percepción de problemas o lagunas de información, de formación de ideas o de hipótesis, de evaluación y modificación de esas hipótesis, unido a la habilidad de comunicar los resultados. Mednick (1964) señala que la creatividad consiste en la formación de nuevas combinaciones de elementos asociativos. Las asociaciones resultan más creativas cuanto más alejados están los elementos asociados. Bruner (1962) citado en Aguilera Hernández (2011), señala que el acto creativo es el que produce una respuesta eficiente y útil. Amabile (1983) señala que la creatividad es la capacidad del individuo de producir un producto que sea novedoso, válido, apropiado y útil, y analiza la importancia de la motivación en la capacidad creativa de las personas. De la Torre (1989) señala que la creatividad es un fenómeno intrínsecamente humano relacionado con la capacidad de captar estímulos, transformarlos. Desde este enfoque la creatividad es vista como capacidad de las personas, no como cualidad. Eisner (1994), expresa que es posible identificar cuatro tipos de conducta en el sujeto creativo: 1. Correr los límites, 2. Invención, 3. Romper los límites y 4. Organización estética. Los tres primeros tipos se caracterizan por la presencia de la novedad. El individuo que corre los límites redefine o extiende los usos que pueden 
tener los objetos o ideas comunes. Esta capacidad creativa es propia de las personas no se encuentran funcionalmente ancladas, y que pueden emplear los objetos con fines para los que los que no fueron creados. La persona que "inventa" es la que combina los objetos de manera tal que produce un objeto nuevo. Santaella (2006) define a la creatividad como la facultad de organizar de algún modo original los elementos del campo perceptivo, de estructurar la realidad, desestructurarla y reestructurarla en formas nuevas (p.90).

Mientras que desde un enfoque socio-cognitivo interactivo,Este enfoque tiene en cuenta a las personas, sus capacidades para desarrollar el pensamiento creativo, el contexto en el que se desenvuelven y su interacción con el entorno. Esta interacción contempla la valoración de los expertos en el campo disciplinar de referencia. Los expertos se configuran como los agentes legitimadores de la valoración de la creatividad. En este sentido, Stella (1953) señala que la creatividad debe ser definida de acuerdo a las condiciones de la cultura en la que se produce. Sternberg, R. y Lubart, T. (1977) definen a la creatividad como la capacidad de producir un producto novedoso. Su concepción de la creatividad se basa en el resultado o producto final y señala que un producto es creativo cuando es original y sostiene que se necesita un ámbito que apoye y legitime el producto creativo. De La Torre (1991) define a la creatividad como una cualidad que trasciende al individuo, no es solo una aptitud personal sino que involucra a su estilo de vida, el contexto, la cultura, los valores y la forma de afrontar los problemas. Considera a la creatividad como un bien social. En su trabajo Para investigar la creatividad, reafirma la postura de Rohdes (1961) que sostiene que la creatividad se analiza a partir de las siguientes perspectivas: la persona creativa, el proceso, el producto y el entorno. Csikszentmihalyi (1998) define a la creatividad como el resultado de la interacción de un sistema conformado por tres elementos: a) una cultura que tiene reglas simbólicas; b) una persona que aporta novedad a ese campo simbólico y c) un ámbito de expertos que valida el acto o el producto creativo. En este sentido Gardner (1995) señala que los investigadores cognitivistas han esclarecido el modo en que los individuos creativos identifican los problemas y los "espacios" de solución para esos problemas, cómo buscan en estos espacios aproximaciones adecuadas al problema planteado y pistas que puedan dar buenos resultados, cómo evalúan situaciones alternativas a los problemas, cómo despliegan recursos de tiempo y energía, cómo deciden cuándo seguir y cuándo no seguir y cómo reflexionan sobre sus propios procesos creativos. Sin embargo, no consideran la influencia del contexto cultural y social en el que se desenvuelven las personas. El contexto funciona como agente motivador y como regulador de la capacidad creativa. Para Csikszentmihalyi (1998) la creatividad es el resultado de la interacción de un sistema conformado por tres elementos: a) una cultura que tiene reglas simbólicas; b) una persona que aporta novedad a ese campo simbólico y c) un ámbito de expertos que valida el acto o el producto creativo. Para Aguilera Hernández (2011), la valoración de la creatividad depende de la sociedad y del momento en histórico en el que se produce. Si es demasiado pronto, un producto creativo puede diluirse porque no existen las condiciones de factibilidad técnica o porque la sociedad no está preparada para comprenderlo. Maher, M. y Fisher, D. (2012) en su trabajo Using AI to evaluate creative designs, presentado en la 2da. Conferencia Internacional sobre Creatividad en Diseño (Glasgow, 2012), señalan que la creatividad es un aspecto de un producto o un proceso, situado y contextualizado. Matilde Obradors (2007), citada en Aguilera Henández (2011), hace la siguiente clasifi- 
cación de las definiciones de creatividad: a) Las definiciones que tienen en cuenta a las personas: Guilford (1950), Amabile (1986) y Torrance (1988); b) las definiciones que tienen en cuenta el contexto social y cultural en que surge la creatividad: Stein (1953), Amabile (1986), Csikszentmihalyi (1998), Gardner (1998); d) las definiciones que consideran el ámbito y las valoraciones de los expertos: Amabile (1986), Sternberg (1977), Gardner (1998), Csikszentmihalyi (1998) y, e) las que definen a la creatividad entendiéndola como un proceso: Wallas (1926) identifica cuatro fases del proceso creativo: preparación, incubación, iluminación y verificación.

Para el presente trabajo de investigación tomaremos como marco orientativo una combinación de las teorías desarrolladas por Guilford $(1950,1967)$, del enfoque pico-cognitivo y el enfoque desarrollado por Csikszentmihalyi (1998), socio-cognitivo, interactivo.

Guilford (1967) en La naturaleza de la inteligencia humana (1967) desarrolla la Teoría de la estructura del intelecto y aplica métodos multivariados de análisis factorial que analizan las cualidades intelectuales que contribuyen en la elaboración del pensamiento creativo. Según esta teoría, las aptitudes más significativas en relación al pensamiento creativo se clasifican en dos categorías: a) la de aptitudes de producción divergente y b) las aptitudes de transformación. Las aptitudes de producción divergente se relacionan con la generación de ideas. En este caso la variedad es un factor destacado y está relacionada con los tipos de fluidez, la flexibilidad y la capacidad de elaboración. El pensamiento divergente depende de la información, del medio y de la disciplina a la que se vincula la persona. Las aptitudes de transformación, en cambio, están relacionadas con la revisión de lo que se experimenta o ya se conoce y con la capacidad para generar formas y pautas novedosas. En este aspecto, la flexibilidad es la que genera las reinterpretaciones y reorganizaciones propias del proceso creativo. El autor define a la fluidez como la capacidad de recuperar la información del caudal de la memoria. Esa capacidad puede expresarse como: a) recordación replicativa (de la información almacenada), y b) recordación de transferencia -que indica de qué manera la persona accede a la información almacenada y la utiliza en nuevas conexiones y asociaciones. En este sentido, Schon (1992), citado en Guilford (1971), señala que la recordación de transferencia es la evocación de la experiencia pasada para afrontar de forma novedosa una situación nueva. En cuanto al factor flexibilidad, Guilford (1967) afirma que es la posibilidad de transformar la información y la capacidad de adaptarla a usos nuevos. Además la flexibilidad está relacionada con una recuperación eficaz de la información que permite reclasificar los datos. La elaboración consiste en producir conexiones y asociaciones significativas. Acerca de las condiciones que afectan al pensamiento creativo, el autor señala a la motivación como fuente determinante del hecho creativo.Guilford (1959) aisló los aspectos específicos del intelecto que pueden condicionar la creatividad. Parte de 3 variables básicas: operaciones, contenido y producto. La variable operaciones se refiere a lo que el organismo hace con la información: a) Cognición: descubrimiento, reconocimiento o comprensión; b) Memoria: retención o almacenamiento; c) Producción divergente: que genera información variada a partir de la información recibida o conocida; d) Producción convergente: que genera información a partir de la información; e) Evaluación: decide sobre la validez de la información. La variable contenido se refiere a la generalidad de la información: a) Figurativo: concreto o percibido; b) Memoria: signos; Semántico: significado. La variable productos refiere a la 
forma que adopta la información como resultado de su procesamiento a) Utilidades: b) Clases: conjuntos de unidades con propiedades comunes; c) Relaciones: conexiones entre unidades y campos; d) Sistemas: estructuras organizadas; e) Transformaciones: cambios o redefiniciones; f) Implicaciones: extrapolaciones, como antecedentes o consecuentes).

Dippo, C. (2013) señala en Evaluating the alternative uses test of creativity, que la creatividad es un factor crítico en el proceso de diseño proyectual. La creatividad orienta dirige la acción del diseñador proponiendo nuevos posibles y nuevas soluciones. El test de pensamiento creativo (TTCT) de Torrance (1962), el test de Asociaciones Remotas (RAT), de Mednick (1964) y los tests de pensamiento divergente de Guiloford (1967), constituye para la autora la piedra angular de la evaluación de la creatividad desde la perspectiva psicocognitiva. Concluye en que el pensamiento divergente es el indicador más significativo del potencial del pensamiento creativo.

Desde el enfoque socio-cognitivo, interactivo, Csikszentmihalyi (1998), define a la creatividad como un proceso por el cual dentro de la cultura resulta modificado un campo simbólico. "La creatividad es cualquier acto, idea o producto que cambia un campo ya existente, o que transforma un campo ya existente en uno nuevo" (p.23). Y la persona creativa es "alguien cuyos pensamientos y actos cambian un campo o establecen un nuevo campo" (p.23). Un campo no puede ser modificado sin el consentimiento explícito o implícito del ámbito responsable de él. (p.47). Csikszentmihalyi (1998) identifica tres elementos o nodos que son centrales en cualquier consideración de la creatividad: a) La persona o talento individual; b) El campo o disciplina en que ese individuo se desempeña; c) El ámbito circundante que emite juicios de valor sobre la calidad de los individuos y productos. Para el autor, la creatividad no es inherente a un solo factor. Las actividades creativas son reconocidas como tales cuando han sido aceptadas en una cultura concreta -el campo-, que consiste en una serie de reglas y procedimientos simbólicos. A su vez, los campos están ubicados en lo que habitualmente llamamos cultura, o conocimiento simbólico compartido por una sociedad particular o por la humanidad. (p.55). Acerca del análisis de la persona creativa, Csikszentmihalyi señala cuatro niveles significativos: subpersonal, personal, impersonal y multipersonal. El análisis subpersonal indica si los individuos creativos tienen constituciones genéticas peculiares o si hay algo extraordinario en la estructura o funcionamiento de su sistema nervioso. El análisis personal, desde la tradición la tradición de la psicología cognitiva investiga los procesos cognitivos que caracterizan a las personas creativas y los aspectos de la personalidad, motivacionales, sociales y afectivos de los creadores. El análisis impersonal vincula a la creatividad con el campo o disciplina en la que se desempeña la persona. Esta perspectiva es de tipo epistemológico. El nivel de análisis multipersonal examina los modos en que los miembros del ámbito (expertos) hacen valoraciones provisionales acerca de la creatividad. Más allá de las características que definen a la persona creativa, el autor señala que el "ámbito" en el que se desarrolla el proceso creativo es de relevancia significativa. El ámbito incluye a todos los individuos que dan acceso al campo disciplinar y su propósito es decidir si una idea o producto nuevo debe incluirse en ese campo.

Desde esta perspectiva socio-cognitiva-interactiva, S. De La Torre (1996) en su trabajo Para investigar la creatividad, reafirma la postura de Rohdes (1961) que sostiene que la creatividad se analiza a partir de las siguientes perspectivas: la persona creativa, el proceso, 
el producto y el entorno. De La Torre detalla los aspectos que comprometen a estos cuatro factores constitutivos de la creatividad: a) persona: los componentes del pensamiento creativo y su proceso tiene origen en el conocimiento previo; b) el proceso creativo: comprende la delimitación en etapas para conocer la evolución e interacción de los conocimientos previos y sus nuevas combinaciones. Indaga la influencia que ejercen las dimensiones cognitivas y afectivas, el papel que juegan la fluidez y la flexibilidad, cuáles son los mecanismos cognitivos que actúan en la resolución de problemas lógico-deductivos y en problemas de carácter divergente, cómo se presentan las ideas importantes, cómo actúa la intuición, entre otros aspectos; c) el producto: pretende desentrañar cuáles son los parámetros para evaluar un producto y determinar si es creativo o no; cuáles son los factores que determinan que un producto sea valioso para el campo disciplinar y para la sociedad; d) el entorno: refiere a cuáles son los factores que tienen influencia en el desarrollo de la creatividad y cuáles son los agentes legitimadores en el campo disciplinar.

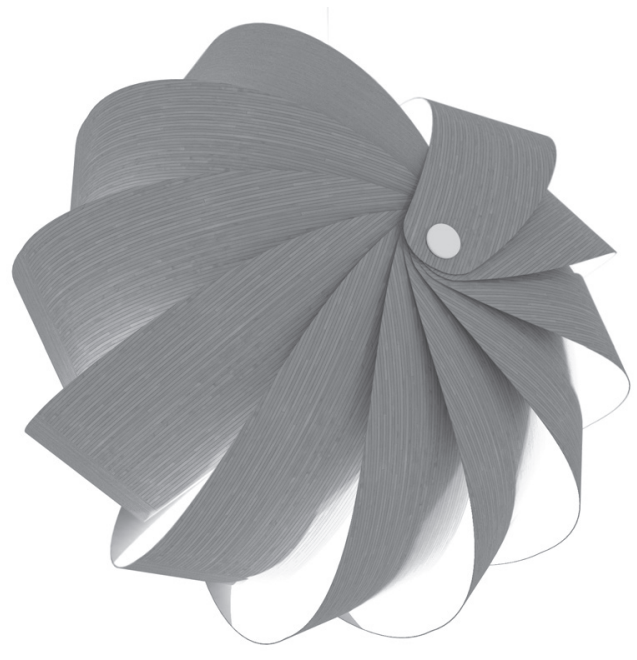

Imagen 2. Universidad de Palermo. Facultad de Diseño y Comunicación. Imágenes que crean productos 3. Volumen 32, (p.32). Marzo 2016. Federico Camusio. Lámpara. Buenos Aires. Argentina.

\section{Enseñanza de la creatividad en Diseño Industrial}

Como mencionáramos al comienzo de este trabajo, el objetivo central de esta investigación es conocer cuáles son los criterios de evaluación de la creatividad utilizados por los docentes de la carrera de Diseño Industrial en la Facultad de Diseño y Comunicación de la Universidad de Palermo. En su declaración de misión la institución expresa: formar, enseñar, investigar y brindar servicios a su comunidad académica y a la sociedad, centrando las miras en el sujeto que aprende y en la satisfacción de sus necesidades, buscando potenciar al máximo sus capacidades. Lo hará formando profesionales en un marco académico inter- 
disciplinario, impulsando el análisis, la creatividad, la capacitación permanente, la creación de conocimientos, ideas y obras - integrando dimensiones cognitivas, éticas y estéticas - en el campo de Diseño y las Comunicaciones. En este contexto la Facultad asume, entre otros, el compromiso de contribuir a la expansión del conocimiento, la difusión de las ideas, la integración de la cultura, la globalización de la educación superior y el cambio del contexto sociocultural en pos del mejoramiento de la condición humana. Inmersa en un contexto sociocultural en cambio constante, la Facultad promueve estrategias y líneas de acción que posibilitan anticiparse a los cambios y actuar como un agente dinamizador de estas transformaciones. (Palermo.edu)

En función de esta declaración y de la dinámica de articulación de carreras, asignaturas y acciones de perfil transdisciplinar, la creatividad configura el denominador común a todas las actividades de la Facultad. Entender cómo se enseña y cómo se evalúa, en este caso en la Carrera de Diseño Industrial, ayudará al desarrollo de estrategias para mejorar desempeños. Tal como indicáramos al comienzo de este trabajo, el Diseño Industrial es considerado una actividad eminentemente creativa cuya preocupación esencial son las personas a las que van dirigidos los productos y servicios diseñados. En La enseñanza de las disciplinas proyectuales, Mazzeo y Romano (2007), las autoras señalan que la creatividad es un elemento central de la etapa de formulación del proyecto. Doberti, citado en Mazzeo y Romano (2007, p.11) afirma que el proceso de diseño proyectual es complejo, multidimensional e implica una progresiva generación que no suele ser lineal. En este proceso de generación de ideas y posibles soluciones, la creatividad se destaca como una variable indispensable para la generación de nuevos posibles. En el proceso inciden factores racionales y sensibles, objetivos y subjetivos, personales y sociales que suelen ser consecuencia de una relación interdisciplinaria.

Para profundizar acerca de este enfoque, describimos la perspectiva de las autoras Mazzeo y Romano (2007) acerca de la enseñanza de las disciplinas proyectuales.

Las autoras señalan que como todo proceso, el proceso de diseño está configurado por etapas que comienzan con una necesidad, luego avanza con distintos grados de certidumbre e incertidumbre, la propuesta o la solución aportada y por último la verificación y validación. Este proceso es de carácter orgánico, ya que en todas y cada una de las etapas, precedentes y posteriores, están presentes las restantes.

A nivel didáctico, el proceso puede organizarse en cuatro etapas. La primera es la etapa de información. Es la que alimenta el punto de partida y debería seguir un análisis riguroso del problema real, con sentido práctico, no especulativo. El relevamiento de datos objetivos y antecedentes de respuestas previas, es el eje central de esta etapa. La segunda etapa es la de formulación. En esta etapa se clarifican y orientan los objetivos del proyecto. En la idea conceptual-formal de la formulación confluyen la lógica y la poética simultáneamente. Esta es la etapa en la que la creatividad es un elemento esencial. Para la autora, es el momento de la síntesis creativa. La capacidad individual deja su impronta en el proceso y en el producto. Sin embargo, la creatividad no puede ser entendida como pura inspiración. Implica la interacción entre el pensamiento de la persona y su interacción con el contexto socio-cultural e institucional, en este caso. (Mazzeo, 2007, p.75). Desde esta perspectiva, y en relación con el enfoque socio-cognitivo-interactivo de la creatividad, sobre el que más adelante profundizaremos, el Diseño Industrial tiene reglas que rigen su actividad y 
procedimientos simbólicos específicos y existe para la disciplina un ámbito (Csikszentmihaly, 1998) que funciona como marco de referencia constituido por los "expertos", que son quienes legitimarán el grado de creatividad del resultado. En esta investigación, el ámbito y la valoración de los "expertos", están configurados por los docentes de la disciplina, que son quienes evaluarán el trabajo de los estudiantes en un contexto institucional normalizado. Tal como el proceso de diseño se desarrolla de forma sistémica, la creatividad necesita de esa misma dinámica para producir respuestas novedosas a problemas o situaciones a resolver. Mazzeo (2007) señala que el conocimiento del campo disciplinar por parte del estudiante es condición fundamental para que la creatividad pueda arrojar aportes significativos y relevantes. Cuanto más conocimiento del campo se tiene, mayores son las posibilidades de producir aportes innovadores. Para la autora, más relevante que las personas creativas, son las acciones creativas y su relación con el campo del conocimiento en el que se producen. Estas acciones deberán ser validadas por quienes tienen el dominio del campo (los "expertos" del ámbito legitimador). La tercera etapa es la de desarrollo. En esta etapa se trata de evitar la disociación de la formulación con la realidad disciplinar ya que la instancia de simulación altera las reglas de juego a las que está sometido el resultado real final. La cuarta etapa es la de materialización y verificación del proyecto. Para algunos teóricos esta etapa no estaría incluida dentro del proceso de diseño. Con distintos grados de prefiguración se llega a la materialización del proyecto para su posterior verificación. Para la autora el aporte central de la creatividad está en la segunda etapa, la de formulación.

Ahora la pregunta es: ¿se puede enseñar la creatividad en disciplinas proyectuales? ¿Cuáles son las circunstancias que favorecen su desarrollo?

Woolfolk (1999) citado en Rojas Morales (2004, p.16) afirma que la creatividad se puede potenciar a través de estrategias de aprendizaje. Partiendo de la premisa que Diseñar es proyectar, crear a partir de los recursos con los que se cuenta y con un propósito determinado (Rojas Morales, 2004, p.9). Como señalan Mazzeo y Romano (2007), el estudiante creador es producto de su tiempo y de su medio. Los objetos que diseña parten de las cosas creadas antes que él. Para que un objeto sea diseñado se requieren ciertas condiciones psicológicas y materiales y su forma va a estar determinada por las precedentes. Avanzaremos sobre la enseñanza de la creatividad desde la perspectiva de distintos autores alineados con el enfoque constructivista, enfoque al que adhiere la Facultad de Diseño y Comunicación de la Universidad de Palermo. Según esta perspectiva, el proceso a través del cual el individuo va construyendo el conocimiento dependerá de dos cuestiones básicas: el conocimiento que ya posee y la actividad interna o externa que realice el individuo. A través de los procesos de aprendizaje el estudiante construye estructuras: formas de organizar la información que le permiten, seleccionar, categorizar, clasificar codificar y evaluar los datos que va recibiendo en relación con alguna experiencia. Carretero, (1993), citado en Rojas Morales (2004), define al constructivismo como un concepto que argumenta que el individuo "no es un mero producto del ambiente, ni un simple resultado de sus disposiciones internas, sino una construcción propia que se va produciendo día a día como resultado de la interacción entre estos dos factores" (p.44)

Para la teoría sociocultural desarrollada por Vigotsky (1917) es precisamente la actividad creadora del hombre la que hace de él un ser proyectado hacia el futuro, un ser que contribuye a crear y modifica su presente. Para el autor la creatividad es toda actividad 
humana cuyo resultado no es la reproducción de lo que ha sucedido en la experiencia, sino la generación de nuevas formas o actividades. La teoría sociocultural sostiene que si los estudiantes están en contacto directo con el problema a resolver, tendrán más elementos para generar mejores soluciones. Además, otro aspecto importante desarrollado por esta teoría es el concepto de la "zona de desarrollo próximo". Tanto el docente como sus pares pueden convertirse en facilitadores para estimular el desarrollo de ideas originales y creativas. El enfoque psicogenético de Piaget (1954), considera a la creatividad como una manifestación de la inteligencia. Así, el pensamiento creativo es propio de los procesos asimilativos que son la transformación subjetiva de la realidad. El docente cumple el papel de facilitador que orienta al alumno a experimentar, evitando la repetición y fomentando la creatividad. (Citado en Rojas Morales, 2004, p.45). La teoría del aprendizaje por descubrimiento de Jerome Bruner (1996) plantea la importancia de fomentar en el estudiante la capacidad de observación y análisis de manera que vaya llenando su mente de imágenes que posteriormente le ayudarán a construir otras nuevas. La teoría de la asimilación y el aprendizaje significativo de Ausubel (1976) impulsa la utilización de mapas conceptuales a través de lo que llamó organizadores. Define dos tipos de organizadores: los organizadores comparativos, que permiten al estudiante relacionar el problema con todos los aspectos del mismo que el ya conoce, y los organizadores expositivos que le ayudarán a generar nuevas ideas a partir de conceptos nuevos. Las teorías del aprendizaje social de Albert Bandura (1986) y la teoría de la cognición situada y el aprendizaje significativo en Díaz Barriga Arceo (2003), enfatizan la relevancia de la interacción de tres ejes: personal, ambiental y conductual. Esta interacción nutre la generación de ideas y acciones originales. (Citados por Rojas Morales, 2004, p.46)

Las teorías mencionadas toman en consideración a la creatividad en distintos niveles de relevancia. Sin embargo, la teoría que podríamos llamar paradigmática, para estimular el desarrollo del pensamiento creativo es la teoría del Pensamiento Lateral y el Pensamiento Paralelo, desarrollada por el psicólogo Edward De Bono en 1967. Ambos tipos de pensamiento impulsan el proceso de resolución de problemas a través de métodos no convencionales o ilógicos. A diferencia del pensamiento vertical, que parte de una idea y va construyendo conocimiento sobre la misma idea de manera lógica y en una sola dirección, el pensamiento lateral se desarrolla de manera no secuencial, ni lógica. El proceso implica un desplazamiento hacia otras direcciones, con diferentes percepciones, conceptos y puntos de partida. El desarrollo del pensamiento lateral tiene como objetivo generar nuevas ideas y nuevos caminos para analizar las cosas. Su dinámica contribuye a liberar la mente de prejuicios al buscar enfoques menos obvios para solucionar los problemas de manera no convencional. Pensar lateralmente genera manifestaciones fluidas, flexibles y abiertas al cambio. El pensamiento paralelo tiene la finalidad de mejorar el empleo de las habilidades de pensamiento. Supone simplemente poner las ideas unas al lado de otras. Existe una exploración genuina del tema de la que después se derivan conclusiones y decisiones por medio de un proceso de diseño. Varias personas pueden aportar ideas para resolver un problema y todas deben ser aceptadas sin ejercer sobre ellas ningún tipo de juicio, lo que permite una verdadera exploración. De esta exploración surgen nuevas perspectivas y respuestas originales a problemas preexistentes. 


\section{Evaluación de la creatividad en Diseño Industrial}

Evaluar la creatividad presenta las dificultades derivadas de la polisemia del término y de la transdisciplinariedad de la creatividad misma. Tomando como punto de partida la rúbrica de evaluación institucionalizada por la Facultad de Diseño y Comunicación de la Universidad de Palermo, la creatividad se presenta como un criterio de evaluación estratégico al momento de definir variables e indicadores que permitan medir el desempeño de los estudiantes de Diseño.

La Rúbrica en cuestión contempla a la Creatividad como un criterio de evaluación que se desagrega en la siguiente escala:

Malo: El proyecto tiene un nivel de creatividad e innovación nulo, incluso menos a los antecedentes estudiados.

Regular: El proyecto presenta una reproducción de proyectos tomados como antecedentes, sin aportes nuevos.

Bueno: El proyecto presentado aporta nuevas propuestas que evidencian una búsqueda propia del estudiante.

Muy bueno: El proyecto cumple con lo requerido, se evidencian aportes propios y crea una identidad que expresa al autor.

Destacado: El proyecto es una creación propia que propone superar y enriquecer a los antecedentes.

En la práctica, la evaluación de los trabajos que presentan los estudiantes se lleva a cabo desde una manera empírica, desde la subjetividad de cada profesor. No se explicita un modelo que sirva como instrumento de análisis durante el proceso de diseño industrial y permita a los estudiantes analizar el grado de creatividad de sus propuestas. Desconocemos cuáles son las mejores prácticas, los procesos motivacionales y cognitivos para para el desarrollo del pensamiento creativo en el espacio de diseño, y por supuesto, las herramientas para medirlo con la precisión adecuada a la disciplina. La rúbrica no propone indicadores específicos que contribuyan a medir el desempeño creativo de los estudiantes. Estos indicadores específicos podrían surgir de las propias definiciones e interpretaciones de la creatividad que detallaremos a continuación, en función de los rasgos específicos de la creatividad planteados por distintos autores.

Sabemos que toda evaluación, forma parte del proceso de enseñanza-aprendizaje, es de carácter integrador ya que toma en cuenta las características de los estudiantes, el contexto social e institucional en el que se encuentra y sirve para reorientar y mejorar las acciones en función de las metas establecidas. En el proceso de evaluación, los criterios sobre los cuales se establecen las clasificaciones deben ser compartidos y conocidos por los estudiantes.

Distintos autores definen los rasgos de la creatividad sobre los que se pueden definir los criterios e indicadores para su evaluación.

Romo (1997), citado en Aguilera Hernández (2011), define tres factores para determinar el criterio de valor y creatividad de un producto: a) La transformación, factor que alude a los nuevos enfoques que se producen al formular nuevas combinaciones y distintas formulaciones de lo ya existente; b) la condensación, que es la capacidad de relacionar y aglutinar 
información que hasta entonces no había sido relacionada. Esto es integrar y simplificar, y c) La aplicabilidad, en este factor el producto creativo da paso a nuevas formas de uso y a la generación de nuevas teorías. Amabile (1983) citada en Allueva (2002), señala que la creatividad está asociada al producto. Desde su perspectiva el pensamiento creativo de resultar en el producto creativo. Para la autora el producto será creativo en la medida en que los expertos en el campo así lo determinen. Las características básicas del producto creativo son la novedad, es decir que resulte impredecible y la adecuación, esto significa que sea útil. Señala tres habilidades cognitivas como componentes de la producción creativa: a) relevantes a un dominio; b) relevantes en creatividad (estilo cognitivo, capacidad asociativa, generación de nuevas ideas); c) motivación hacia la tarea: actitudes hacia la tarea, percepción de la propia motivación. Al mismo tiempo propone cinco etapas en el proceso creativo: a) presentación: se recoge la información referente al problema a resolver; b) preparación: se orienta la información disponible en dirección a la resolución del problema; c) generación de respuestas: estas respuestas deben ser novedosas. Aquí, igual que en la preparación, influye la motivación; d) validación de la idea; e) aplicación, se comprueba si la idea ha resultado exitosa. Si es exitosa, la idea se aplica; si no es exitosa se reinicia el proceso.

Desde la perspectiva de la creatividad como producto, MacKinnon (1978), citado en Aguilera Hernández (2011), señala tres condiciones del producto creativo: a) presencia de una respuesta poco frecuente o novedosa; b) la verdadera creatividad debe servir como solución a un problema, adaptarse a una situación determinada y c) guardar relación con la realidad. Es en el producto donde la creatividad se manifiesta de manera concreta y tangible. Es donde se materializan las aptitudes creativas aplicadas durante el proceso. Maher, M. y Fisher, D. (2012) en su trabajo Using AI to evaluate creative designs, presentado en la 2da. Conferencia Internacional sobre Creatividad en Diseño (Glasgow, 2012), señalan que la creatividad es un aspecto situado y contextualizado. Evaluar el fenómeno de la creatividad implica encontrar patrones, criterios e indicadores aplicables a distintos casos y campos disciplinares que valoran a la creatividad como un pilar ya sea en el proceso o en el producto creativo, siempre situado y contextualizado en situaciones específicas. Los autores proponen un modelo de aproximación a la evaluación de la creatividad basado en el uso de la Inteligencia Artificial y cuyos criterios esenciales para evaluarla son: la innovación, el valor y el factor sorpresa. Para los autores, la innovación es una característica esencial del producto creativo, sin embargo no está claro qué aspectos de la innovación están directamente asociados a la creatividad. Los autores sostienen que la innovación es la medida de la distancia entre las diferencias de productos similares de un mismo grupo. Acerca del valor, el trabajo plantea que el producto debe satisfacer los criterios de desempeño específicos del campo disciplinar y debe mejorar en alguna medida la vida de las personas y de la sociedad. Para medir el valor, esta investigación propone el uso de métricas que midan la distancia entre el valor propuesto por el nuevo producto y los valores ya existentes en grupos de productos similares. Para los autores el factor sorpresa es un aspecto de la creatividad que señalamos cuando decimos que un producto es creativo porque supera las expectativas previas previstas para los productos de su tipo o clase.

Amabile (1982), citada en Maher, M. y Fisher, D. (2012), en respuesta la dificultad para estandarizar los criterios de evaluación de la creatividad aplicables a múltiples campos, 
desarrolló la técnica CAT (Conssenssual Assesment Technique) en la que la creatividad es evaluada por un grupo de expertos en el campo disciplinar de pertenencia. Amabile define una serie de características relevantes para evaluar en cada campo. Por ejemplo, en arte y diseño: innovación, idea, grado de variación en las formas y grado de complejidad. Candy y Zafer (2009) en Understanding and Evaluating Creativity, proponen una matriz de evaluación de la creatividad que contempla tres perspectivas: nivel de creatividad del público objetivo, grado de creatividad del producto, habilidades de la persona creativa. Para medir el nivel o de creatividad en el público objetivo, el estudio sostiene que el factor determinante es el grado de relacionamiento significativo del público con el objeto es la variable determinante. Los indicadores a tener en cuenta son: cambios en la conducta y cambios conceptuales respecto de la idea inicial. Acerca del grado de creatividad en el producto o resultado, se tiene en cuenta el impacto que el proceso creativo produce en el resultado final. En este caso deben definirse factores constitutivos esenciales del campo o de la disciplina y establecer escalas o métricas para medir el grado de presencia de esos factores en el producto o resultado final. En cuanto a las habilidades de la persona creativa, se tiene en cuenta el ámbito o el campo de su competencia y en función de ello se determinan las características a evaluar teniendo en cuenta el grado de experiencia, la selección de contenidos, las asociaciones en el momento de la ideación y las técnicas utilizadas. Los autores enfatizan la relevancia del contexto, el ámbito, y el campo disciplinar al momento de seleccionar los criterios de evaluación de la creatividad (Csikszentmihalyi, 1998) y destacan la importancia de la motivación en el acto creativo (Amabile, 1983).

Mitjáns Martínez (1993) en Cómo evaluar la creatividad, analiza las implicancias metodológicas que tiene la consideración del carácter "personológico" de la creatividad para su evaluación y sus determinantes psicológicos. Mitjáns Martínez señala que para valorar en nivel de creatividad de las personas en un área determinada, se deben utilizar tareas o problemas relacionados con las especificidades de esa área. De esa manera se alcanzará una mayor implicación de esa persona en la tarea asignada. (p.105)

La Universidad de Rochester, desarrolla la versión Synergistic Rubric 1.1, en la que señala que el pensamiento creativo solo puede desarrollarse en un marco disciplinar determinado. Desde esta perspectiva, los estudiantes deben tener conocimientos previos y habilidades desarrolladas sobre la disciplina en la que aplicarán la creatividad para poder establecer las conexiones y asociaciones que posibiliten una instancia superadora de síntesis y elaboración de "lo nuevo". A partir de un conocimiento sólido del tema a abordar, el estudiante estará en mejores condiciones para atravesar los límites de lo conocido y proponer soluciones únicas y novedosas, nuevas combinaciones y asociaciones que suponen la toma de riesgos y la tolerancia a la incertidumbre. La rúbrica desarrollada involucra al proceso de resolución de problemas (proceso en el que es esencial la aplicación del pensamiento creativo) y enfatiza más en la calidad del proceso que en el producto final.

Casakin et al. (2011) en Motivación para la Creatividad en Estudiantes de Diseño: Implementación de una Estrategia Pedagógica, señalan que además de ser práctico y funcional el producto de diseño de be ser valioso e innovador. Desde esta perspectiva el pensamiento creativo se constituye como un elemento sustancial para la creación de productos de diseño. Así la creatividad es un requisito fundamental para la solución de exitosa de problemas de diseño industrial. Los autores centran su atención en la influencia del factor motivación 
en el desarrollo de la capacidad y el pensamiento creativo. Señalan que tanto la motivación intrínseca en la que los estudiantes se involucran con la tarea por su propio interés (Amabile, 1983) citado en Casakin et al. (2011), como la motivación extrínseca, que refiere al compromiso con la actividad para alcanzar un objetivo externo, no completan la interpretación de la influencia de la motivación en el proceso creativo de los estudiantes de diseño industrial o arquitectónico. En este sentido, los autores señalan que la Teoría Cognitiva de la Orientación desarrollada por Kreitler y Kreitler (1982), Kreitler (2004), citados en Casakin et al. (2011), es el enfoque que mejor desarrolla las investigaciones sobre la influencia de la motivación en el pensamiento creativo. Los diseñadores creativos se caracterizan por tener flexibilidad cognitiva, espontaneidad, originalidad e independencia de juicio. Para los autores, el aporte más significativo de la teoría Cognitiva de la Orientación, es que el comportamiento en todos los dominios -incluidos el diseño y la creatividad, es una función de la motivación. Esta conceptualización de la motivación refiere a temas o campos disciplinares específicos.

Santaella (2006) en su trabajo Evaluación de la creatividad, presenta una propuesta para evaluar la creatividad, que define los siguientes criterios e indicadores: Originalidad: capacidad del individuo para generar ideas y productos cuya característica es única, de gran interés y aportación social. Iniciativa: actitud humana para idear y emprender actividades, disposición personal para protagonizar y desarrollar ideas en primer término. Fluidez: capacidad para producir ideas en cantidad de manera permanente y espontánea. Flexibilidad: capacidad para organizar los hechos dentro de diversas categorías. Divergencia: Capacidad del individuo para analizar lo opuesto, visualizar lo diferente, contrariar el juicio y utilizar el pensamiento lateral. Sensibilidad: capacidad del individuo para percibir y expresar el mundo en sus múltiples dimensiones. Elaboración: capacidad para formalizar las ideas, planear y desarrollar proyectos. Desarrollo. Autoestima: es la valoración de sí mismo, la confianza en la persona basada en la conciencia real de sus posibilidades y potencialidades. Motivación: es la relación entre los aspectos cognitivos y los afectivos en función de la resolución de problemas. Independencia: libertad elegir los caminos para comprender, formular y realizar las tareas. Innovación: creatividad aplicada a través del uso óptimo de los recursos para convertir algo en otra cosa. (p.120)

Lee, J. H. et al. (2012) en Evaluating Creativity in Parametric Design Processes presentan un modelo de aproximación formal para la descripción e identificación de la creatividad desde ambas perspectivas, el proceso y el producto. El planteo combina un protocolo de análisis para codificar las actividades cognitivas relacionadas con el diseño, e indicadores formalmente consensuados para evaluar la creatividad en productos paramétricos. El esquema de codificación se basa en: representación, percepción y búsqueda de una solución. Los indicadores de evaluación son producto de la elaboración de un panel de expertos. El trabajo ofrece un procedimiento para evaluar la creatividad en diseño paramétrico aún en estado de verificación que contempla las siguientes instancias: análisis de la creatividad personalidad (define la estrategia de pensamiento de diseño), proceso de diseño (experimentación, entrevistas), producto de diseño (evaluación del resultado, funcionalidad), mapeo y análisis correlacional. Protocolo de análisis: a) nivel de creatividad y patrones cognitivos; b) evaluación del panel de expertos: criterios de evaluación y evaluación relativa. 


\section{Consideraciones metodológicas del trabajo de campo}

El presente trabajo pretende indagar cuáles son los criterios de evaluación de la creatividad utilizados por docentes de las asignaturas proyectuales de la carrera de Diseño Industrial en una Universidad privada con sede en la Ciudad Autónoma de Buenos Aires. La investigación se llevará a cabo en el período semestral del calendario académico correspondiente a 2016-2. Se entrevistará a 5 docentes de asignaturas proyectuales de la carrera de Diseño Industrial. El grupo de docentes seleccionados está conformado por docentes de las asignaturas DI III, DI IV y DI VI.

Objetivo General: Conocer cuáles son los criterios de evaluación de la creatividad que utilizan los docentes de asignaturas proyectuales de la carrera de Diseño Industrial.

Objetivos específicos:

- Develar cómo interpretan el concepto de creatividad los docentes de las asignaturas proyectuales de Diseño Industrial.

- Describir cuáles son los factores o aspectos de la creatividad a los que los docentes otorgan mayor relevancia disciplinar.

- Explorar cuáles son los indicadores que utilizan para evaluar esos rasgos o aspectos de la creatividad.

Enfoque: Interpretativo-Hermenéutico

El alcance previsto es descriptivo y la Idea directriz es:

La creatividad en diseño industrial es la variable que garantiza una producción superadora de los antecedentes. Plantea una nueva mirada a un mismo problema, realiza aportes y propone nuevos caminos.

\section{Resultados}

Resultados trabajo de campo. Corresponde a las primeras entrevistas. (Previo a las segundas entrevistas). 


\begin{tabular}{|c|c|c|c|c|c|}
\hline & Docente DW & Docente RC & Docente DD & Docente DLC & Docente CC \\
\hline \multirow[t]{3}{*}{$\begin{array}{l}\text { ¿Qué es la creatividad? } \\
\text { ¿A qué definición o } \\
\text { enfoque adhiere? }\end{array}$} & $\begin{array}{l}\text { Resolver un } \\
\text { problema técnico } \\
\text { utilizando la menor } \\
\text { cantidad de recur- } \\
\text { sos y haciendo un } \\
\text { uso más eficiente } \\
\text { de los procesos. } \\
\text { Es un método } \\
\text { de acción, no de } \\
\text { expresión. }\end{array}$ & \multirow{3}{*}{$\begin{array}{l}\text { Es la capacidad } \\
\text { para encontrar } \\
\text { soluciones no } \\
\text { tradicionales } \\
\text { a problemas } \\
\text { nuevos. Es una } \\
\text { propiedad o tipo } \\
\text { de pensamiento, } \\
\text { relacionado con el } \\
\text { descubrimiento. } \\
\text { Es el uso de pen- } \\
\text { samiento lateral o } \\
\text { divergente y refiere } \\
\text { a las inteligencias } \\
\text { múltiples. }\end{array}$} & $\begin{array}{l}\text { Es la manera } \\
\text { de resolver } \\
\text { problemas } \\
\text { frente a } \\
\text { determinadas } \\
\text { limitaciones. } \\
\text { Requiere partir } \\
\text { de conocimien- } \\
\text { tos previos, de } \\
\text { antecedentes } \\
\text { conocidos } \\
\text { para poder } \\
\text { modificar la } \\
\text { realidad. Se } \\
\text { debe conocer } \\
\text { el campo. }\end{array}$ & \multirow{3}{*}{$\begin{array}{l}\text { Lo que se } \\
\text { presenta como } \\
\text { una respuesta } \\
\text { diferente o } \\
\text { evolutiva en } \\
\text { relación a lo } \\
\text { que se viene } \\
\text { haciendo en } \\
\text { un objeto o en } \\
\text { un proceso. } \\
\text { Siempre vin- } \\
\text { culado con la } \\
\text { innovación. }\end{array}$} & $\begin{array}{l}\text { Es un término } \\
\text { sobrevalorado. } \\
\text { La creatividad } \\
\text { está subordi- } \\
\text { nada a los ob- } \\
\text { jetivos. Implica } \\
\text { conocer los } \\
\text { antecedentes, } \\
\text { detectar los va- } \\
\text { cíos y a través } \\
\text { de la reflexión } \\
\text { y la producción } \\
\text { Ilenar esos } \\
\text { vacíos con } \\
\text { una mirada o } \\
\text { un producto } \\
\text { nuevo. }\end{array}$ \\
\hline & $\begin{array}{l}\text { En DI no hablamos } \\
\text { de creatividad. }\end{array}$ & & $\begin{array}{l}\text { Adhiero a la } \\
\text { teoría Csik- } \\
\text { szentmihaly } \\
\text { del fluir de la } \\
\text { creatividad, } \\
\text { relacionada } \\
\text { con el placer. } \\
\text { Con equilibrar } \\
\text { dificultades } \\
\text { y destrezas } \\
\text { frente a las } \\
\text { limitaciones. }\end{array}$ & & $\begin{array}{l}\text { Es relacionar } \\
\text { objetos que } \\
\text { vengan de } \\
\text { mundos } \\
\text { diferentes y } \\
\text { generar algo } \\
\text { nuevo. }\end{array}$ \\
\hline & $\begin{array}{l}\text { Hablamos de } \\
\text { metodología para la } \\
\text { resolución de pro- } \\
\text { blemas en relación } \\
\text { a las limitaciones } \\
\text { de los materiales y } \\
\text { procesos. }\end{array}$ & & & & $\begin{array}{l}\text { Es reducir la } \\
\text { cantidad de } \\
\text { pasos para } \\
\text { resolver un } \\
\text { problema y } \\
\text { facilitarle la vida } \\
\text { a la gente. }\end{array}$ \\
\hline $\begin{array}{l}\text { ¿Es la creatividad un } \\
\text { factor relevante para la } \\
\text { disciplina? }\end{array}$ & $\begin{array}{l}\text { La creatividad en } \\
\text { sí, no es relevante } \\
\text { para el DI. No es un } \\
\text { tema central. Sólo y } \\
\text { en ciertos casos, en } \\
\text { el eje de materiales } \\
\text { y procesos. En } \\
\text { tecnologías. }\end{array}$ & $\begin{array}{l}\text { No tan rele- } \\
\text { vante como la } \\
\text { materialidad, la } \\
\text { funcionalidad y } \\
\text { la tecnología. En } \\
\text { DI la creatividad } \\
\text { queda subordina- } \\
\text { da a la función y } \\
\text { a los materiales. } \\
\text { Se centra en } \\
\text { aspecto estético } \\
\text { o morfológico, } \\
\text { que siempre están } \\
\text { subordinados a la } \\
\text { función. }\end{array}$ & $\begin{array}{l}\text { Es relevante en } \\
\text { la medida que } \\
\text { esté vinculada } \\
\text { a los objetivos. } \\
\text { Que produzca } \\
\text { una respuesta } \\
\text { diferente, origi- } \\
\text { nal a partir de } \\
\text { las limitaciones } \\
\text { que plantea el } \\
\text { campo. }\end{array}$ & $\begin{array}{l}\text { Es relevante } \\
\text { porque puede } \\
\text { hacer una } \\
\text { diferencia } \\
\text { cualitativa o } \\
\text { cuantitativa } \\
\text { si se refiere } \\
\text { a la solución } \\
\text { especíica de } \\
\text { un problema } \\
\text { de diseño, } \\
\text { ya sea en la } \\
\text { metodología o } \\
\text { en el objeto. }\end{array}$ & $\begin{array}{l}\text { Es un descrip- } \\
\text { tor más. Tal vez } \\
\text { no sea el más } \\
\text { relevante. La } \\
\text { funcionalidad y } \\
\text { las interfaces, } \\
\text { es decir la } \\
\text { relación del } \\
\text { objeto con el } \\
\text { usuario, están } \\
\text { por delante. }\end{array}$ \\
\hline
\end{tabular}

continúa $>>$ 


\begin{tabular}{|c|c|c|c|c|c|}
\hline \multirow{2}{*}{$\begin{array}{l}\text { ¿Considera que existe } \\
\text { algún aspecto, rasgo } \\
\text { o característica de } \\
\text { la creatividad más } \\
\text { relevante que otros } \\
\text { para el DI? }\end{array}$} & La originalidad. & \multirow[b]{2}{*}{$\begin{array}{l}\text { La originalidad. } \\
\text { Ser original en las } \\
\text { respuestas para } \\
\text { resolver problemas } \\
\text { o limitaciones de } \\
\text { una manera dife- } \\
\text { rente. Conocer los } \\
\text { antecedentes, la } \\
\text { investigación pre- } \\
\text { via es fundamental } \\
\text { para proponer } \\
\text { respuestas diferen- } \\
\text { tes. Otro es la } \\
\text { flexibilidad: cuanto } \\
\text { más amplio sea el } \\
\text { rango de solucio- } \\
\text { nes, más flexible } \\
\text { es el pensamiento } \\
\text { y por lo tanto más } \\
\text { creativo. }\end{array}$} & \multirow[b]{2}{*}{$\begin{array}{l}\text { El fluir de la } \\
\text { creatividad. } \\
\text { Ese estado } \\
\text { que amplía el } \\
\text { horizonte de } \\
\text { soluciones, } \\
\text { relacionado } \\
\text { con el placer. }\end{array}$} & \multirow[b]{2}{*}{$\begin{array}{l}\text { Los relacio- } \\
\text { nados con la } \\
\text { innovación, } \\
\text { en el proceso } \\
\text { y en el objeto } \\
\text { producido. } \\
\text { Cuando se } \\
\text { puede acoplar } \\
\text { lo estético o } \\
\text { morfológico a } \\
\text { lo tecnológico } \\
\text { y funcional. }\end{array}$} & \multirow[b]{2}{*}{$\begin{array}{l}\text { La capacidad } \\
\text { de relacionar } \\
\text { objetos, } \\
\text { reflexiones } \\
\text { y miradas } \\
\text { diferentes. La } \\
\text { creatividad } \\
\text { nace en la } \\
\text { investigación. } \\
\text { En el conoci- } \\
\text { miento de los } \\
\text { anteceden- } \\
\text { tes. No es } \\
\text { expresión libre. } \\
\text { Hay un foco un } \\
\text { objetivo que } \\
\text { guía. Que limita } \\
\text { y condiciona } \\
\text { la creatividad } \\
\text { en función de } \\
\text { lo que hay que } \\
\text { resolver. }\end{array}$} \\
\hline & $\begin{array}{l}\text { La ruptura con lo } \\
\text { conocido. }\end{array}$ & & & & \\
\hline \multirow[t]{2}{*}{$\begin{array}{l}\text { Acerca de la enseñanza } \\
\text { de la creatividad. } \\
\text { ¿Utiliza estrategias o } \\
\text { técnicas para estimular } \\
\text { la creatividad en los } \\
\text { estudiantes de DI? }\end{array}$} & \multirow[t]{2}{*}{$\begin{array}{l}\text { Ejercicios o planes } \\
\text { de acción para } \\
\text { resolver problemas } \\
\text { de manera eficaz } \\
\text { con la mayor can- } \\
\text { tidad de limitantes } \\
\text { posibles. Relaciona- } \\
\text { dos a materiales } \\
\text { y procesos. A lo } \\
\text { tecnológico. A la } \\
\text { acción, no a la } \\
\text { expresión. }\end{array}$} & $\begin{array}{l}\text { Se utilizan } \\
\text { estrategias de } \\
\text { pensamiento di- } \\
\text { vergente. Miradas } \\
\text { desprovistas de } \\
\text { prejuicio y provis- } \\
\text { tas de emociones. } \\
\text { Salir de la lógica } \\
\text { del producto y su } \\
\text { función y entrar } \\
\text { en la lógica del } \\
\text { marketing y la } \\
\text { comunicación. }\end{array}$ & \multirow{2}{*}{$\begin{array}{l}\text { Propongo } \\
\text { ejercicios con } \\
\text { objetivos claros } \\
\text { y conocidos } \\
\text { por todos, } \\
\text { en los que se } \\
\text { definen las } \\
\text { limitaciones y } \\
\text { los recursos } \\
\text { disponibles y } \\
\text { a partir de ahí } \\
\text { hay que produ- } \\
\text { cir algo nuevo. } \\
\text { Siempre tiene } \\
\text { que mediar } \\
\text { un conflicto a } \\
\text { resolver. Es un } \\
\text { valor agregado. }\end{array}$} & \multirow[t]{2}{*}{$\begin{array}{l}\text { Utilizamos } \\
\text { paneles } \\
\text { representativos } \\
\text { y objetos exis- } \\
\text { tentes. Pueden } \\
\text { alterar su } \\
\text { función inicial } \\
\text { pero deben ser } \\
\text { perfectamente } \\
\text { funcionales a } \\
\text { otra categoría, } \\
\text { la nueva, } \\
\text { la que el } \\
\text { estudiante } \\
\text { decidió que } \\
\text { fuera la nueva } \\
\text { categoría. }\end{array}$} & $\begin{array}{l}\text { Las relaciona- } \\
\text { das con en- } \\
\text { contrar vacíos } \\
\text { y relacionar } \\
\text { universos }\end{array}$ \\
\hline & & $\begin{array}{l}\text { Quebrar la lógica } \\
\text { matemática. Uti- } \\
\text { lizar la lógica de } \\
\text { otras disciplinas. }\end{array}$ & & & $\begin{array}{l}\text { El uso de } \\
\text { metáforas. } \\
\text { Ejercicios de } \\
\text { pensamiento } \\
\text { lateral, asocia- } \\
\text { tivo, en red. }\end{array}$ \\
\hline $\begin{array}{l}\text { ¿Se puede evaluar la } \\
\text { creatividad? }\end{array}$ & $\begin{array}{l}\text { No evaluamos la } \\
\text { creatividad. Evalua- } \\
\text { mos la capacidad } \\
\text { de resolver la mayor } \\
\text { cantidad de limita- } \\
\text { ciones sin aumentar } \\
\text { el costo del pro- } \\
\text { ducto, mejorando } \\
\text { su eficiencia y su } \\
\text { aporte estético. }\end{array}$ & $\begin{array}{l}\text { Sí. En relación a } \\
\text { la superación de } \\
\text { los antecedentes } \\
\text { previos. Cuando la } \\
\text { respuesta ofrece } \\
\text { una repuesta con } \\
\text { significación que } \\
\text { agrega valor al } \\
\text { producto en base } \\
\text { a un vínculo distin- } \\
\text { to al habitual. }\end{array}$ & $\begin{array}{l}\text { Sí. Teniendo } \\
\text { claro el objetivo } \\
\text { y hasta a dón- } \\
\text { de se pueden } \\
\text { alejar de lo } \\
\text { conocido. }\end{array}$ & $\begin{array}{l}\text { Sí. La eva- } \\
\text { luación de la } \\
\text { creatividad es } \\
\text { subjetiva. }\end{array}$ & $\begin{array}{l}\text { Sí. Siempre } \\
\text { explicitando } \\
\text { los criterios } \\
\text { y el objetivo } \\
\text { del trabajo. } \\
\text { Generando un } \\
\text { instrumento } \\
\text { que la haga } \\
\text { visible. El es- } \\
\text { tudiante debe } \\
\text { saber en qué } \\
\text { se le pide que } \\
\text { sea creativo. Y } \\
\text { tiene que estar } \\
\text { consciente } \\
\text { de cuál fue su } \\
\text { aporte creativo. }\end{array}$ \\
\hline
\end{tabular}

continúa $>>$ 


\begin{tabular}{|c|c|c|c|c|c|}
\hline \multirow[t]{3}{*}{$\begin{array}{l}\text { ¿Cuáles son los crite- } \\
\text { rios e indicadores que } \\
\text { utiliza para evaluar la } \\
\text { creatividad? }\end{array}$} & \multirow[t]{3}{*}{$\begin{array}{l}\text { Equilibrio en la } \\
\text { disposición de las li- } \\
\text { mitaciones tecnoló- } \\
\text { gicas para resolver } \\
\text { un problema. }\end{array}$} & \multirow[t]{3}{*}{$\begin{array}{l}\text { La originalidad, } \\
\text { la flexibilidad, la } \\
\text { intersubjetividad, } \\
\text { las emociones. }\end{array}$} & \multirow{3}{*}{$\begin{array}{l}\text { La relación } \\
\text { entre recursos } \\
\text { disponibles, } \\
\text { limitantes y } \\
\text { solución. Se } \\
\text { definen los } \\
\text { objetivos y los } \\
\text { criterios en } \\
\text { función de los } \\
\text { parámetros a } \\
\text { medir: función, } \\
\text { morfología, } \\
\text { tecnología. }\end{array}$} & \multirow{3}{*}{$\begin{array}{l}\text { La diferencia } \\
\text { entre lo que ya } \\
\text { existe y lo que } \\
\text { propone el es- } \\
\text { tudiante como } \\
\text { novedad. Igual } \\
\text { es subjetivo. }\end{array}$} & $\begin{array}{l}\text { Capacidad } \\
\text { para encontrar } \\
\text { el vacío entre } \\
\text { antecedentes. }\end{array}$ \\
\hline & & & & & $\begin{array}{l}\text { Capacidad de } \\
\text { explicitar cuál } \\
\text { es el aporte } \\
\text { creativo. }\end{array}$ \\
\hline & & & & & $\begin{array}{l}\text { La autonomía } \\
\text { del estudiante } \\
\text { y su capacidad } \\
\text { para liderar el } \\
\text { discurso de } \\
\text { sobre su pro- } \\
\text { pio proyecto. }\end{array}$ \\
\hline \multirow[t]{2}{*}{ Otras valoraciones } & \multirow[t]{2}{*}{$\begin{array}{l}\text { La respuesta de } \\
\text { diseño no tiene que } \\
\text { ser creativa. Tiene } \\
\text { que ser eficaz. La } \\
\text { creatividad no es } \\
\text { relevante. Valo- } \\
\text { ramos la ruptura, } \\
\text { pero no es un tema } \\
\text { central en DI. }\end{array}$} & $\begin{array}{l}\text { La enseñanza del } \\
\text { Dl está en manos } \\
\text { de profesionales, } \\
\text { sin preparación } \\
\text { para la enseñanza. } \\
\text { Enseñan como } \\
\text { les enseñaron. No } \\
\text { abren el juego a la } \\
\text { intersubjetividad ni } \\
\text { a la interdisci- } \\
\text { plinariedad. Es } \\
\text { necesario desarro- } \\
\text { llar herramientas } \\
\text { pedagógicas } \\
\text { para los docentes } \\
\text { profesionales del } \\
\text { diseño. Los crite- } \\
\text { rios de evaluación } \\
\text { deben explicitarse } \\
\text { a los estudiantes. }\end{array}$ & \multirow[t]{2}{*}{$\begin{array}{l}\text { La motivación } \\
\text { es muy impor- } \\
\text { tante para ser } \\
\text { creativo. La } \\
\text { curiosidad, el } \\
\text { conocimiento } \\
\text { de la disciplina, } \\
\text { la iteración. }\end{array}$} & \multirow[t]{2}{*}{$\begin{array}{l}\text { La disciplina } \\
\text { está en pleno } \\
\text { proceso de } \\
\text { cambio de } \\
\text { nombre. De } \\
\text { Diseño Indus- } \\
\text { trial a Diseño } \\
\text { Objetual. Re- } \\
\text { lacionado con } \\
\text { la no serialidad } \\
\text { de los objetos. } \\
\text { La no indus- } \\
\text { trialización. }\end{array}$} & \multirow[t]{2}{*}{$\begin{array}{l}\text { La creatividad } \\
\text { no es algo de } \\
\text { la inspiración, } \\
\text { del no control. } \\
\text { Hay que } \\
\text { acorralar el } \\
\text { concepto, } \\
\text { explicitarlo } \\
\text { y luego eva- } \\
\text { luarlo. }\end{array}$} \\
\hline & & $\begin{array}{l}\text { La emoción juega } \\
\text { un rol importante } \\
\text { en la producción } \\
\text { creativa. }\end{array}$ & & & \\
\hline
\end{tabular}

\section{Resultado posterior a las segundas entrevistas. Aportes de las segundas entrevistas}

Se volvió a entrevistar al docente DW, Director de la carrera de Diseño Industrial y a la docente DD, coordinadora del área de Producción de los Estudiantes.

Estas segundas entrevistas se realizaron en pleno período de exámenes finales. Y los entrevistados traen ejemplos del momento del examen.

En esta oportunidad, y en función de los resultados de las primeras entrevistas, esta segunda entrevista estuvo centrada en tres ejes: 

a) Acerca de la relevancia de la creatividad en DI
b) Acerca de la enseñanza de la creatividad en DI. Estrategias, técnicas, dinámicas.
c) Criterios de evaluación de la creatividad en DI

Estos ejes conducen a focalizar las entrevistas en los datos centrales a relevar: definición de creatividad y su relevancia para la disciplina, ¿cómo se enseña? y ¿qué criterios utilizan los docentes para evaluarla?

\begin{tabular}{|c|c|c|}
\hline & Docente DW & Docente DD \\
\hline $\begin{array}{l}\text { Acerca de la relevancia } \\
\text { de la creatividad en DI }\end{array}$ & $\begin{array}{l}\text { Solo es relevante cuando ayuda } \\
\text { a resolver el problema del manejo } \\
\text { de las limitaciones técnicas para } \\
\text { alcanzar una solución eficaz a un } \\
\text { problema concreto, funcional. } \\
\text { El DI es un proyecto de acción, no } \\
\text { de expresión. } \\
\text { Es la capacidad de reorganizar } \\
\text { ideas o datos precedentes para } \\
\text { producir algo nuevo, un aporte, una } \\
\text { solución eficiente. } \\
\text { El problema es la polisemia del } \\
\text { término creatividad. }\end{array}$ & $\begin{array}{l}\text { Ser creativo en diseño implica dar } \\
\text { soluciones reales, eficaces, o eficientes } \\
\text { a un problema relacionado con ciertas } \\
\text { limitaciones. Es un modo de pensamiento } \\
\text { no lógico. La creatividad es un estado de } \\
\text { comprensión sintética que vincula mente } \\
\text { y cuerpo, los sentidos y la sensibilidad... } \\
\text { pero siempre con una pata racional, de } \\
\text { bagaje cognitivo, racional. Siempre ligada } \\
\text { a la resolución de un problema tecnológi- } \\
\text { co, funcional, si no, no es diseño, es arte. }\end{array}$ \\
\hline \multirow[t]{3}{*}{$\begin{array}{l}\text { Acerca de la enseñanza de la } \\
\text { creatividad en DI. Estrategias, } \\
\text { técnicas, dinámicas. }\end{array}$} & \multirow{3}{*}{$\begin{array}{l}\text { Actividades, ejercicios que } \\
\text { desarrollen la capacidad para } \\
\text { reorganizar ideas y recursos con un } \\
\text { fin específico. } \\
\text { Transformar algo corriente en algo } \\
\text { original, nuevo. } \\
\text { Proponer la mayor cantidad de limi- } \\
\text { taciones tecnológicas posibles para } \\
\text { la resolución de un problema. }\end{array}$} & $\begin{array}{l}\text { Uso de lógicas diferentes, no lineales. } \\
\text { Pensamiento lateral. }\end{array}$ \\
\hline & & $\begin{array}{l}\text { Ejercicios para el uso de recursos senso- } \\
\text { riales, emotivos, cenestésicos. }\end{array}$ \\
\hline & & $\begin{array}{l}\text { Ejercicios para obtener la mayor cantidad } \\
\text { de respuestas a partir de limitaciones. }\end{array}$ \\
\hline $\begin{array}{l}\text { Criterios de evaluación de la } \\
\text { creatividad en DI }\end{array}$ & $\begin{array}{l}\text { Se evalúa la investigación de los } \\
\text { materiales, de los antecedentes y } \\
\text { luego las posibles combinaciones } \\
\text { o procesos originales o novedo- } \\
\text { sos que generen a partir de esos } \\
\text { antecedentes conocidos. } \\
\text { La cantidad de combinaciones } \\
\text { posibles para la transformación en } \\
\text { algo nuevo, original, que solucione } \\
\text { un problema, que funcione. }\end{array}$ & $\begin{array}{l}\text { Se mide la eficiencia en el manejo de las } \\
\text { limitaciones de (materiales o de procesos). } \\
\text { Se evalúan las etapas de la interface, el } \\
\text { recorrido de las asociaciones para produ- } \\
\text { cir una solución novedosa (flexibilidad). } \\
\text { La fluidez, relacionada con la cantidad } \\
\text { de respuestas posibles para la solución } \\
\text { eficaz del problema. } \\
\text { La originalidad, cuando la respuesta eficaz } \\
\text { es única o está más alejada de las solu- } \\
\text { ciones que dieron los antecedentes. }\end{array}$ \\
\hline Otras valoraciones & $\begin{array}{l}\text { Diseñar diseñadores. Analogía con } \\
\text { el diseño de objetos, productos o } \\
\text { procesos. }\end{array}$ & $\begin{array}{l}\text { El fluir de la creatividad. La creatividad flu- } \\
\text { ye y se expande cuando está relacionada } \\
\text { con el placer. }\end{array}$ \\
\hline
\end{tabular}


Las apreciaciones obtenidas nos permiten una aproximación más específica al objetivo general y a los objetivos específicos de la investigación.

De la confrontación de los resultados de la primera y la segunda ronda de entrevista se destacan las siguientes valoraciones:

Acerca de la conceptualización de la creatividad y su relevancia en el campo disciplinar, los docentes entrevistados coinciden en los siguientes aspectos:

La creatividad es la capacidad para resolver problemas o encontrar soluciones eficaces frente a limitaciones tecnológicas. Es la capacidad para reorganizar ideas y antecedentes de manera eficaz para producir una solución diferente. El DI es un proyecto de acción, no de expresión. Si no resuelve un problema funcional, no es DI, es arte. (Elaboración, originalidad, flexibilidad, pensamiento divergente).

Acerca de la relevancia de la creatividad en DI, manifiestan que queda subordinada a la eficacia de la función, la materialidad y la tecnología.

Acerca de la enseñanza de la creatividad, los entrevistados proponen:

Ejercicios para desarrollar la capacidad de reorganizar ideas, antecedentes y recursos con un fin específico (flexibilidad y elaboración).

Ejercicios para transformar algo corriente en algo nuevo (originalidad).

Ejercicios con la mayor cantidad de limitantes posibles para la resolución de un problema (flexibilidad, pensamiento divergente, elaboración).

Ejercicios para obtener la mayor cantidad de respuestas a partir de limitaciones (fluidez)

Uso de lógicas diferentes, no lineales (pensamiento divergente)

Ejercicios para el uso de recursos sensoriales, emotivos y cenestésicos.

Acerca de los criterios que utilizan para evaluar la creatividad, expresan:

Evaluar la investigación y el conocimiento de los antecedentes.

Evaluar la cantidad y calidad de las combinaciones posibles.

Evaluar la eficacia para resolver el problema en cuestión.

Evaluar la eficiencia en el manejo de limitaciones.

Evaluar la eficacia de las etapas de la interface (atributos del objeto y su relación con el usuario)

Evaluar la originalidad de la respuesta al problema a al manejo de las limitaciones.

\section{Conclusiones}

Para orientar esta investigación se tomará como punto de partida los factores psico-cognitivos de la creatividad desarrollados por Guilford $(1950,1971,1994)$ y Amabile $(1982,1983)$ y los factores socio-cognitivos/ interactivos desarrollados por Csikszentmihalyi (1998).

Además de profundizar en la etapa de Formulación del proceso de diseño y su relación con la creatividad, esta investigación tomará en cuenta la influencia de la creatividad en las dimensiones excluyentes del campo disciplinar -funcionalidad, estética, morfología y tecnología, (Coneval, 2016). Esta delimitación permitirá conocer cómo evalúan los decentes los aspectos de la creatividad relevantes para cada una de las dimensiones.

Desde los puntos de vista de los enfoques psico-cognitivo y psico-socio-cognitivo, se indagará sobre cómo se evalúan los siguientes rasgos de la persona creativa: fluidez, flexibi- 
lidad, originalidad, elaboración, pensamiento divergente, estilo cognitivo, capacidad asociativa, generación de nuevas ideas, motivación hacia la tarea; cuáles son las características del ambiente que estimulan la creatividad; cual es el papel de los agentes legitimadores de la creatividad, en este caso, los docentes.

\section{Notas}

1. Universidad de Palermo. Facultad de Diseño y Comunicación. Imágenes que crean productos 3. Volumen 32, (p.74). Marzo 2016. Laura Catalina Arenas Uribe. Buenos Aires. Argentina.

2. Universidad de Palermo. Facultad de Diseño y Comunicación. Imágenes que crean productos 3. Volumen 32, (p.32). Marzo 2016. Federico Camusio. Lámpara. Buenos Aires. Argentina.

Link a la publicación: https://fido.palermo.edu/servicios_dyc/publicacionesdc/vista/detalle_publicacion.php?id_libro=589

\section{Listas de Referencias Bibliográficas}

Aguilera Hernández, R. (2011). Análisis de los modelos que evalúan la creatividad en los productos publicitarios. Universidad Autónoma de Barcelona. España. Disponible en: http://www.recercat.cat/handle/2072/181399

Allueva, P. (2002). Desarrollo de la creatividad: Diseño y evaluación de un programa de intervención. Universidad de Zaragoza. Zaragoza. España. Disponible en: file://C:/Users/ Usuario/Downloads/Dialnet-DesarrolloDeLaCreatividad-2881043.pdf

Ambile, T. M. (1983). The Social Psychology of Creativity: a Componential Conceptualization. Journal of Personality and Social Psychology. 45, 2, 375-376

Amabile, T. M. (1982) The Social Psychology of Creativity: A Consensual Assessment Technique. Journal of Personality and Social Psychology, 43, 5, 997-1013.

Association of American Colleges and Universities (2014). Creative Thinking Value Rubric. Disponible en: https://manoa.hawaii.edu/assessment/resources/rubrics/CreativeThinking_value.pdf

Arenas, E. (2002). Diseño e instrumental de un modelo multifactorial de la creatividad para obtener el perfil de rendimiento creativo de los comunicadores visuales y profesionales afines. Revista de Investigación Universitaria Interdisciplinaria. 1, 49-56. Universidad Simón Bolívar. México.Disponible en: http://www.usb.edu.mx/attachments/article/342/2002.pdf Brown, T (2008) Design Thinking. Harvard Business Review. Disponible en: http://s3.amazon. com/academia.edu.documents/43520771/p02_brown-design-thinking.pdf

De Bono, E. (1991) El pensamiento lateral. Manual de creatividad. Barcelona: Paidós.

Candy, l. y Bilda, Zafer. (2009) Understanding and Evaluating Creativity. ACM Creativity and Cognition. Disponible en: http://research.it.uts.edu.au/creative/linda/CC09TUTE/ CC09Candy_Bildahandout.pdf 
Casakin, H. y Kreitler, S. (2006). Evaluating creativity in design problem solving. Design Research Society. International Conference in Lisbon 2006.Disponibleen:

http://www.iade.pt/drs2006/wonderground/proceedings/fullpapers/DRS2006_0083.pdf

Casakin, H. y Kreitler, S. (2011). The cognitive profile of creativity in design. Thinking Skills and Creativity, Volume 6, Issue 3.Recuperado el 26-05-15 enhttp://www.sciencedirect. com/science/article/pii/S187118711100040X

Casakin, H. y Kreitler, S. (2011). Motivación para la Creatividad en Estudiantes de Diseño: Implementación de una Estrategia Pedagógica. Actas de Diseño, 11, 55-60. Centro de Estudios de Diseño. Facultad de Diseño y Comunicación. Universidad de Palermo. Buenos Aires. Argentina.

Coneval (2016) Términos de referencia de la evaluación de diseño. Consejo Nacional de Evaluación de la Política de Desarrollo Social. México. Disponible en: http://www.coneval.org.

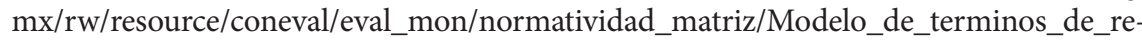
ferencia_evaluacion_diseno_final.pdf

Creative Thinking Value Rubric (s/f) Association of American Colleges and Universities. Disponible en: https://www.aacu.org/value/rubrics/creative-thinking

Csikszentmihalyi, M. (1998). Creatividad. El fluir y la psicología del descubrimiento y la invención. Barcelona: Paidós.

De Bono, E. (1991) El pensamiento lateral. Manual de creatividad. Barcelona: Paidós.

De la Torre, S. (1989). Evaluación de la Creatividad. TAEC. Madrid: Escuela Española. Citado en: Garaigordobil, M. y Torres, E. (1996). Evaluación de la creatividad en sus correlatos con inteligencia y rendimiento académico. Tarraconensis. Revista de Psicología. Vol. XVIII (1) pp. 87-98. Recuperado de: http://www.sc.ehu.es/ptwgalam/art_completo/tarraco1.PDF

Díaz Barriga Arceo, F. (2003) Cognición situada y estrategias para el aprendizaje significativo. REDIE. Revista Electrónica de Investigación Educativa. 5, 2. Disponible en: http:// www.redalyc.org/articulo.oa?id $=15550207$

Di Bella, D. (2005) Apuntes sobre la creatividad y la enseñanza del Diseño. Reflexión Académica en Diseño y Comunicación, 6 (74-76). Buenos Aires: Centro de Estudios de Diseño. Facultad de Diseño y Comunicación. Universidad de Palermo.

Dippo, C. (2013) Evaluating the alternative uses test of creativity. Proceedings of the National Conference on Undergraduate Research (NCUR) 2013. University of Wisconsin, La Crosse, WI. 2013.

Eisner, E. (1994). Creatividad y salud psicológica en la adolescencia. En R. Strom (comp.) Creatividad y educación (pp.37-46). Barcelona: Paidós.

Garaigordobil, M. y Torres, E. (1996). Evaluación de la creatividad en sus correlatos con inteligencia y rendimiento académico. Tarraconensis. Revista de Psicología. Vol. XVIII (1) pp. 87-98. Recuperado de: http://www.sc.ehu.es/ptwgalam/art_completo/tarraco1.PDF Gardner, H. (1995) Mentes creativas. (pp.37-62). Barcelona: Paidós.

Gardner, H. (2001). La inteligencia reformulada. Las inteligencias múltiples en el Siglo XXI. Barcelona: Paidós.

Gay, A. y Samar, L. (2007) El diseño industrial en la historia. Centro de Cultura Tecnológica. Argentina: Ediciones TEC.

Guilford, J., Lagemann, J., Eisner, E., Singer, J., Wallach, M., Kogan, N., Sieber, J., Torrance, E. (1994).Creatividad y educación. R.D. Strom. (Comp.) Barcelona: Paidós. 
Guilford, J. (1994) La creatividad: pasado, presente y futuro. En R. Strom (comp.) Creatividad y educación (pp.9-23). Barcelona: Paidós

González Cruz, M. et al. (2008) La estrategia de Creatividad sistemática Triz con equipos multidisciplinares de Diseño de Producto. DYNA. 83, 6, 337-350. Disponible en: http:// portales.puj.edu.co/proyecto_andar/images/pdf/Publicaciones/Articulodyna.pdf

González Romo, R. (2007) Dimensiones del proceso creativos del investigador en psicología en México. Enseñanza e investigación en psicología Vol. 12, N1. Recuperado el 28-05-14 en http://www.cneip.org/documentos/revista/CNEIP_12-1/Gonzalez_Romo.pdf

Imágenes que crean productos 3. En Proyectos de Estudiantes de Diseño Industrial de la Facultad de Diseño y Comunicación de la Universidad de Palermo. Buenos Aires. Marzo, 2016.

Laime Pérez, M. (2005). La evaluación de la creatividad. Liberabit. Revista de Psicología, num. 11. (pp. 35-39). Recuperado de: http://www.redalyc.org/articulo.oa?id=68601105

Lee, J. H., Gu, N., Jupp, J., \& Sherratt, S. (2012, June). Evaluating creativity in parametric design processes and products: a pilot study. In Proceedings of 5th International Conference on Design Computing and Cognition, College Station, TX, USA (Vol. 79).Disponible en: http://mason.gmu.edu/ jgero/conferences/dcc12/DCC12DigitalProceedings/Digital\%20pdf/Lee.pdf

Maher, M. y Fisher, D. (2012) Using AI to evaluate creative designs. Proceedings of the 2 nd. International Conference on Design Creativity.1, 45-54. Glasgow. Scotland. Disponible en: https://www.designsociety.org/publication/31854/ds_73-1_proceedings_of_the_2nd_international_conference_on_design_creativity_volume

Mazzeo, C. y Romano, A. (2007) La enseñanza de las disciplinas proyectuales. Buenos Aires: Nobuko.

Mitjáns Martínez, A. (1993) Cómo evaluar la creatividad. Revista cubana de psicología. 10, 2. Facultad de Psicología. Universidad de la Habana. Disponible en: http://pepsic. bvsalud.org/pdf/rcp/v10n2-3/03.pdf

Monreal, C. (2000). Qué es la creatividad. Madrid: Editorial Biblioteca Nueva.

Piffer, D. (2012) Can creativity be measured? An attempt to clarify the notion of creativity and general directions for future research. Thinking Skills and Creativity, Volume 7, Issue 3, December 2012, Pages 258-264. Disponible en: http://www.sciencedirect.com/science/ article/pii/S1871187112000326

Rhodes M, (1961) An Analysis of Creativity. The Phi Delta Kappan 42, 305-310. Disponible en: http://www.jstor.org/stable/20342603?seq=1\#page_scan_tab_contents

Rochester University (s/f).Synergistic Rubric 1.1Dsiponibleen: https://www.rit.edu/affiliate/ weimpact/documents/FinalWEIMPACT_Synergistic\%20Rubric\%201\%201\%20(2).pdf

Rojas Morales, M. E. (2004) La creatividad desde la perspectiva de la enseñanza del Diseño Industrial en la Universidad Iberoamericana. México: Universidad Iberoamericana A.C. Disponible en: http://www.bib.uia.mx/tesis/pdf/014374/014374.pdf

Santaella, M. (2006) La evaluación de la creatividad. SAPIENS, v7, n2. Caracas. Disponible en: http://www2.scielo.org.ve/scielo.php?script=sci_arttext\&pid=S131758152006000200007\&lng=es\&nrm=is..\&tlng=es

Schon, D. (1992). La formación de profesionales reflexivos. Paidós: Barcelona.

Sternberg, R. (1996) Inteligencia exitosa. Buenos Aires: Paidós

Sternberg, R. (1999) Estilos de pensamiento. Buenos Aires: Paidós 
Synergistic Rubric Version 1.1. Rochester Institute of Technology. 2013.Disponible en: https://www.rit.edu/affiliate/weimpact/documents/FinalWEIMPACT_Synergistic\%20 Rubric\%201\%201\%20(2).pdf

Torrance, E. (1997). Creativity in the classroom. Washington: NEA. Citado en: Garaigordobil, M. y Torres, E. (1996). Evaluación de la creatividad en sus correlatos con inteligencia y rendimiento académico. Tarraconensis. Revista de Psicología. Vol. XVIII (1) pp. 87-98. Recuperado de: http://www.sc.ehu.es/ptwgalam/art_completo/tarraco1.PDF.

Wolf, D. (2004). ¿Diseñar diseñadores? Procesos y Productos. Experiencias pedagógicas en Diseño y Comunicación. En Reflexión Académica en Diseño y Comunicación, 5 (p.209). Buenos Aires: Centro de Estudios de Diseño y Comunicación. Facultad de Diseño y Comunicación. Universidad de Palermo.

Woolfolk, A. (2010) Psicología educativa. México: Pearson Educación. Disponible en: https:// crecerpsi.files.wordpress.com/2014/03/libro-psicologia-educativa.pdf

\title{
Portales digitales
}

ICSID. Industrial Design Definition. Disponible en: www.icsid.org/about/definition/ www.palermo.edu

\section{Bibliografía metodológica}

Hernández Sampieri, R. (2010) Metodología de la Investigación. Ed. 5. México: McGrawHill Valles, M. (1997). Técnicas cualitativas de investigación social. Madrid: Síntesis S.A.

Wainerman, C. y Sautu, R. (1997). La trastienda de la investigación. Buenos Aires: Belgrano

\begin{abstract}
This article explores the criteria for creativity evaluation used in the career of Industrial Design. The article begins with a disciplinary introduction to Industrial Design that allows inferring the relevance of creativity in the design process. Then it deploys different approaches on the conceptualization of creativity from which the distinguishing features arise that can be evaluated. For the development of this stage, the psycho-cognitive approaches (related to the cognitive skills and abilities of Industrial Design students) and socio-cognitive-interactive (contextual, social and cultural) were addressed. The article describes different perspectives and theories about the teaching of creativity, the analysis of the process of evaluation of creativity and then delves into the definitions and positions of disciplinary experts regarding the object of research: the evaluation of creativity in Industrial Design
\end{abstract}

Keywords: Evaluation - creativity - industrial design - pedagogical criteria - ability learning 
Resumo: Este trabalho explora os critérios de avaliação da criatividade utilizados na carreira de Design Industrial. O artigo começa com uma introdução disciplinar ao Design Industrial que permite inferir a relevância da criatividade no processo de design. Depois, implementa diferentes abordagens sobre a conceptualização da criatividade, a partir das quais surgem as características distintivas que podem ser avaliadas. Para o desenvolvimento desta etapa, foram abordadas as abordagens psico-cognitivas (relacionadas às habilidades cognitivas e habilidades dos alunos de Design Industrial) e sócio-cognitivo-interativas (contextuais, sociais e culturais). $\mathrm{O}$ artigo descreve diferentes perspectivas e teorias sobre o ensino da criatividade, a análise do processo de avaliação da criatividade e, em seguida, investiga as definições e posições de especialistas em disciplinas sobre o objeto da pesquisa: a avaliação da criatividade em Design Industrial.

Palavras chave: Avaliação - criatividade - design industrial - critérios pedagógicos - capacidade - aprendizagem

[Las traducciones de los abstracts fueron supervisadas por el autor de cada artículo] 